\title{
Treatment of rheumatoid arthritis with levamisole: long-term results and immune changes
}

\author{
LORNE A. RUNGE, ROBERT S. PINALS, AND RUSSELL H. TOMAR
}

From the Departments of Medicine, Rehabilitation Medicine and Pathology, State University of New Yor $\overrightarrow{6}$ Upstate Medical Center, Syracuse, USA

SUMMARY We treated 29 rheumatoid arthritis patients with levamisole. On the basis of a $25 \%$ improvement in any 3 of 6 measurements $95 \%$ of the patients had a favourable response withi釉 20 weeks. However, $64 \%$ of the patients discontinued levamisole by 40 to 60 weeks because of rash or secondary treatment failures. Delayed skin reactivity to streptokinase-streptodornase increase $\mathbb{P}^{\mathrm{O}}$ significantly in the entire treatment group, but there was an inverse correlation between skin test enhancement and clinical response. There was no overall change in lymphocyte response t $\vec{Q}$ phytohaemagglutinin (PHA) after 4 and 16 weeks of treatment, but seven patients with enhancee lymphocyte responsiveness to PHA experienced an earlier clinical response to levamisole. Treatment with levamisole frequently results in clinical improvement in rheumatoid arthritis, but this is not clearly related to a stimulatory effect on cell-mediated immunity. Its long-term usefulness may be limited by a high incidence of relapse and rash.

Our previous double-blind study (Runge et al., 1977) comparing levamisole to placebo indicated a favourable effect in rheumatoid arthritis (RA). Depressed cell mediated immunity (CMI) has been demonstrated in rheumatoid arthritis both by phytohaemagglutinin (PHA) stimulation (Lance and Knight, 1974; Lockshin et al., 1975; Horowitz and Garrett, 1977) and delayed skin test response to streptokinase-streptodornase (SK-SD) (Houba et al., 1964; Andrianakos et al., 1977). Levamisole resulted in improved CMI in RA (Huskisson et al., 1976) and in other conditions with depressed CMI (Verhaegen et al., 1977). Therefore we measured PHA stimulation and delayed skin test response to SK-SD in the open phase portion of our clinical trial to assess the relationship between improved CMI and clinical effectiveness. We also investigated the duration of treatment necessary for response to levamisole and its long-term benefits and side effects.

\section{Patients and methods}

Thirty patients with active RA, treated only with nonsteroidal anti-inflammatory drugs for the

Accepted for publication May 5, 1978

Correspondence to Dr L. Runge, State University Hospital, 750 E. Adams Street, Syracuse, New York 13210, USA. previous 3 months, gave informed consent an entered a double-blind levamisole-placebo triaf The levamisole dosage was $50 \mathrm{mg}$ twice a day for 4 consecutive days each week. After 16 weeks the code was broken and the placebo group then received levamisole. One patient on placebo discontinue treatment prior to taking levamisole, leaving $2 \overline{9}$ patients as the basis for this report. The protocos allowed dosage adjustment after 16 weeks of treatment. The dose was usually decreased if the patient improved or developed an adverse effect, or increased if there was an inadequate clinical response? Clinical examinations were performed at the beginning, 2 weeks, 4 weeks, and every 4 weeks. thereafter. Items recorded included: duration of morning stiffness, grip strength, number of tender joints, number of swollen joints, number and size o\$ subcutaneous nodules, and physician's and patient's subjective opinion of overall improvement an\& possible untoward effects. A Westergren sedimentå tion rate (ESR), $C$-reactive protein (CRP), chemica profile (SMA 12), and urine analysis were obtained at each visit.

Lymphocyte transformation tests were performe in triplicate with PHA (PHA-P, Difco), 1-500 1-100, and 1-50.4 $410^{5}$ mononuclear cells separatee on a Ficoll-Hypaque gradient (LSM Biometrics Rockville, Md.) were cultured in flat bottome 
micro wells (Costar) in RPMI (Hepes) and 9\% autologous serum. One microcurie ${ }^{3} \mathrm{H}$-thymidine ( 5 curies per $\mathrm{mM}$, Amersham-Searle) was added on day 2 and harvested 18 hours later on to filter paper, washed with TCA, and dried. Radioactivity was determined by liquid scintillation counting (Hartzman et al., 1972). Counts per minute were averaged for each concentration, and PHA stimulation was determined by measuring the area under the dose response curve (Silverman et al., 1976). PHA stimulation tests were done prior to treatment, after 4 weeks, and again at 16 weeks in 14 patients who had been assigned to the placebo group in the double-blind phase of the study.

Intradermal skin tests were performed at time 0 and again at 16 weeks with $0.1 \mathrm{ml}$ of the following antigens: PPD (5 TU Connought), monilia (Dermatophytin-0, 1-100, Hollister-Stier), histoplasmin (Parke-Davis), and SK-SD (Varidase, 100/25 units per $\mathrm{ml}$, Lederle). Induration and erythema at 48 hours were measured as the mean of two diameters at $90^{\circ}$ to each other. Analysis of skin tests included 25 patients.

The life table technique was used to determine the rapidity of response and was constructed by defining a response as a $25 \%$ improvement in any 3 of 6 measurements, a change which was felt to be clinically significant. These included grip strength, number of swollen joints, number of tender joints, ESR, CRP, and subjective improvement. All 29 treated patients contributed to the rate of response illustrated by this method. The same definition was used for the placebo group. The differences in clinical measurements in placebo and levamisole treated patients has been published previously (Runge et al., 1977).

The significance of differences in various measurements on the same patients before and after treatment was assessed by the paired Student's $t$ test, whereas differences between different groups were assessed with the unpaired $t$ test. In each instance the $P$ value reflects the two-tailed test of significance. The difference in rate of clinical improvement, using the life table analysis format, was assessed by the log rank test (Peto et al., 1977).

\section{Results}

Twenty of 21 patients who finished a 20-week course of levamisole showed clinical improvement, a $95 \%$ response rate by life table analysis (Fig. 1). Improvement began at 2 weeks and reached a plateau at 20 weeks. Fig. 2 illustrates the response rate from the original double-blind trial, comparing the levamisole and placebo treated groups. The placebo group seemed to respond initially: 4 of 13

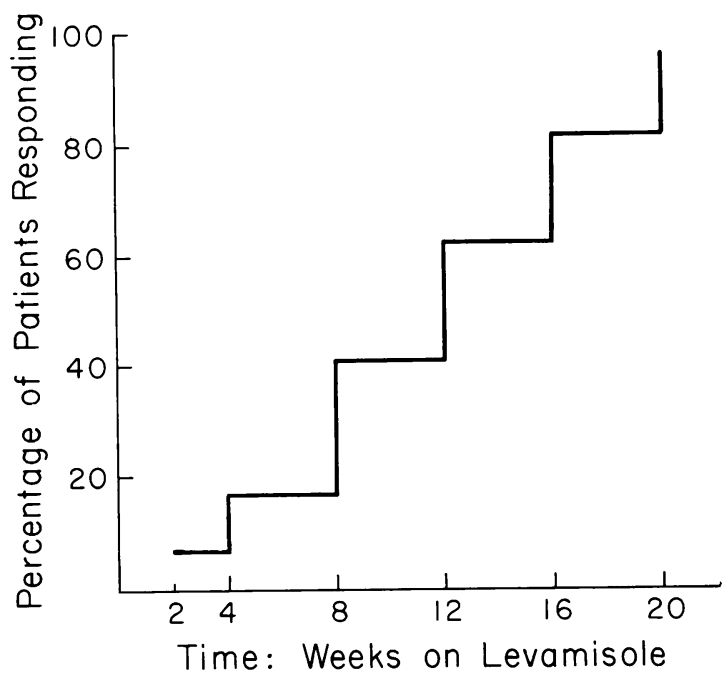

Fig. 1 Rate of clinical improvement in patients during levamisole treatment. See text for definition

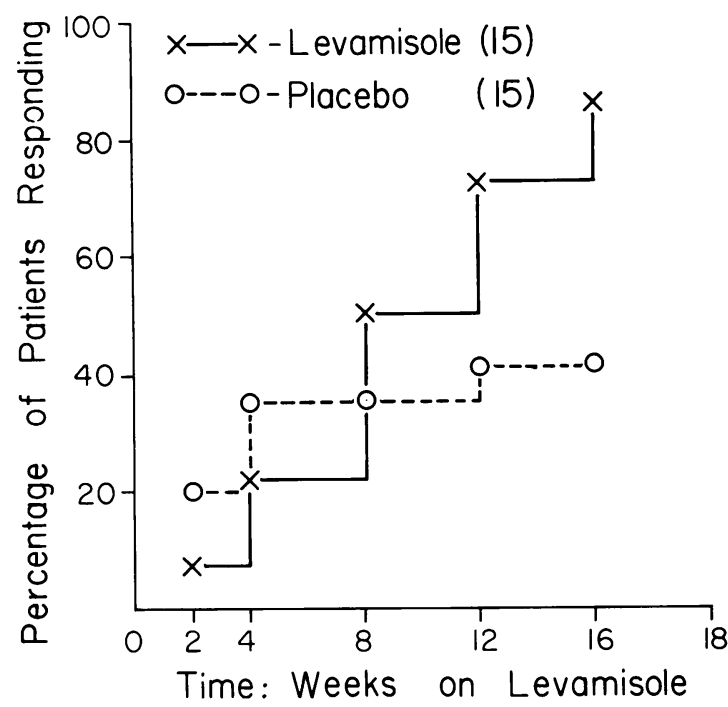

Fig. 2 Rate of improvement during levamisole and placebo treatment-double-blind phase

patients by 4 weeks, but only 1 more responded later in the trial (12 weeks). These 2 curves are not significantly different, but the trend in favour of levamisole later in the trial is apparent. Levamisole induced significant changes in all 6 measures by 16 weeks (Runge et al., 1977).

One patient failed to show benefit and 8 others were unable to complete the 20-week programme owing to side effects (Table 1). Of 21 patients 
remaining on the medication beyond 20 weeks 10 more discontinued treatment over the ensuing 40 weeks owing to recurrence of disease or side effects. By 40 to 60 weeks $64 \%$ of the patients had discontinued levamisole. Rash, usually pruritic with erythematous macules or urticaria, was the commonest reason for stopping treatment. One patient developed severe erythema multiforme and a second had a rash which closely resembled a previous gold-induced dermatitis. However, patients who had previously developed gold rashes were not likely to develop rash on levamisole.

Six patients discontinued levamisole owing to insufficient benefit. One never responded (primary failure), and 5 others responded initially but then relapsed (secondary failure). In an attempt to overcome the relapse the dosage was increased to 150 $\mathrm{mg}$ a day, 4 days a week, but without benefit. One of the patients treated in this manner also developed a rash. The other reasons for stopping treatment include mild leucopenia (WBC, 3200; 65\% neutrophils) in one patient at 12 weeks and possible aggravation of dysmenorrhea in another patient at 16 weeks.

Table 2 illustrates the response to 4 delayed skin test antigens during 16 weeks of levamisole or placebo treatment. The reactions to only 1 of them, SK-SD, increased significantly. Those patients with

Table 1 Number of treatment failures during levamisole administration according to duration of therapy

\begin{tabular}{lrrrr}
\hline & Weeks & & & \\
& $0-16$ & $17-32$ & $33+$ & Total \\
\hline Subjects at risk & 29 & 21 & 12 & \\
Therapeutic failure & 0 & 2 & 4 & 6 \\
$\quad$ Primary & 0 & 1 & 0 & 1 \\
$\quad$ Secondary & 0 & 1 & 4 & 5 \\
Discontinued due to & & & & \\
$\quad$ side effects & 8 & 2 & 2 & 12 \\
$\quad$ Rash & 6 & 2 & 2 & 10 \\
$\quad$ Other & 2 & 0 & 0 & 2 \\
\hline
\end{tabular}

the least enhancement of skin erythema to SK-ST showed the greatest clinical response to levamisole: The same trend occurred with induration (Table $3 \overrightarrow{\sqrt{3}}$ There was no significant correlation between the intensity of the pretrial skin test response to SK-SE and clinical improvement on treatment.

Seven patients showed improvement in lymphocyt transformation (group A), while the other 7 (grou B) showed depression (Figs. 3 and 4). By definition group A had a significantly greater PHA response at 4 and 16 weeks than at time $0(P<0.005)$, and group B had a significantly depressed PHA responsi $(\mathrm{P}<0.05)$. Group A mitogen responses before levamisole were significantly lower than those of group B $(P<0.0025)$ (Table 4). The patients if

Table 3 Mean change in skin test responsiveness related to degree of clinical improvement

\begin{tabular}{llll}
\hline \multirow{2}{*}{$\begin{array}{l}\text { Number of parameters } \\
\text { improved at } 16 \text { wks }\end{array}$} & \multicolumn{2}{l}{ mm change in skin test } \\
\cline { 2 - 4 } \multicolumn{1}{l}{$n$} & Induration & Erythema \\
\hline 1 & 5 & $11 \cdot 6 \pm 13 \cdot 7$ & $15 \cdot 2 \pm 9 \cdot 3$ \\
2 & 4 & $6 \cdot 4 \pm 10 \cdot 5$ & $7 \cdot 0 \pm 5 \cdot 4$ \\
3 & 5 & $2 \cdot 2 \pm 13 \cdot 5$ & $7 \cdot 7 \pm 7 \cdot 2$ \\
4 & 3 & $3 \cdot 3 \pm 5 \cdot 8$ & $0 \cdot 2 \pm 10 \cdot 1$ \\
5 & 5 & $0 \cdot 6 \pm 8 \cdot 4$ & $7 \cdot 1 \pm 9 \cdot 0$ \\
6 & 1 & $-6 \cdot 5$ & -10 \\
Correlation with & & \\
clinical improvement & -0.40 & $-0.47^{*}$ \\
\hline
\end{tabular}

* $\mathbf{P}<0.05$.

Table 4 Differences in clinical characteristics

\begin{tabular}{|c|c|c|c|c|c|}
\hline & $\begin{array}{l}\text { Grou } \\
\text { No. }\end{array}$ & $\begin{array}{l}\text { A } \\
\text { Value }\end{array}$ & $\begin{array}{l}\text { Grou } \\
\text { No. }\end{array}$ & $\begin{array}{l}\text { B } \\
\text { Value }\end{array}$ & $P(A \vee B)$ \\
\hline Initial PHA response & 6 & 420 & 7 & 1341 & $<0.0025$ \\
\hline Change at $1 \mathrm{mo}$ & 6 & +864 & 6 & -797 & NS \\
\hline Change at $4 \mathrm{mo}$. & 5 & +1192 & 4 & -956 & NS \\
\hline Age (years) & 7 & 48 & 7 & 62 & $<0.005$ \\
\hline Duration of arthritis & 7 & 10 & 7 & 21 & NS \\
\hline Weight (kg) & 7 & $68 \cdot 2$ & 7 & $63 \cdot 2$ & NS \\
\hline ASA dose (g/day) & 5 & $4 \cdot 3$ & 4 & $2 \cdot 8$ & NS \\
\hline Sex, male: female & & $1: 6$ & & $1: 6$ & NS \\
\hline
\end{tabular}

Table 2 Skin test results prior to and after 16 weeks of levamisole or placebo treatment. Overall indicates the total response for all four skin tests

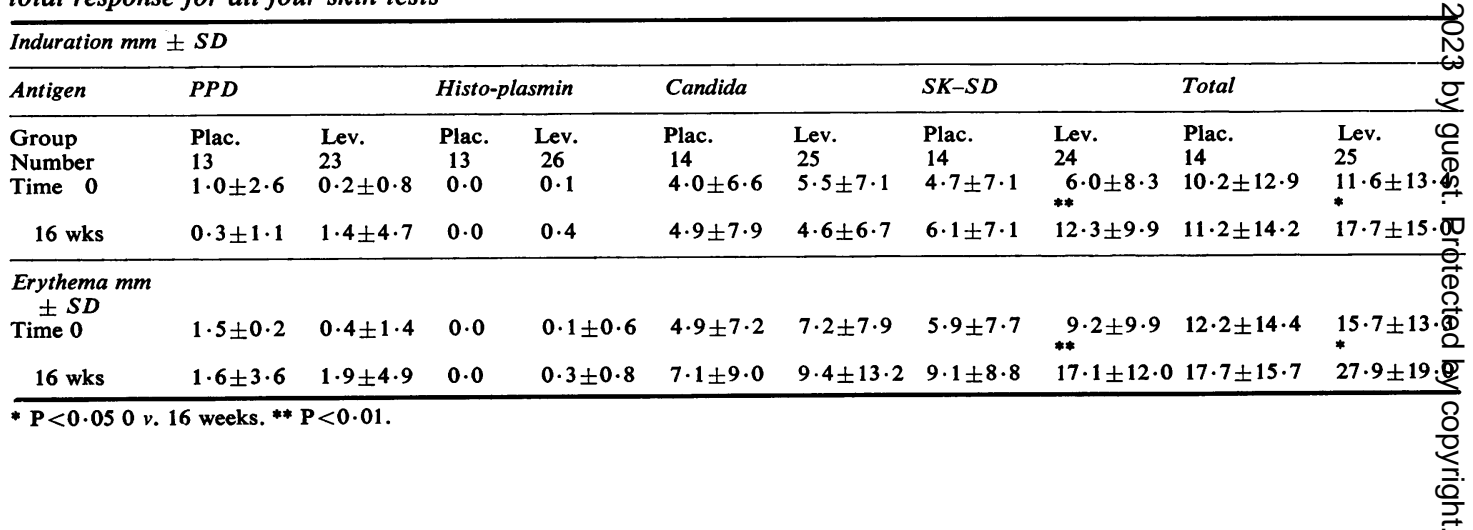




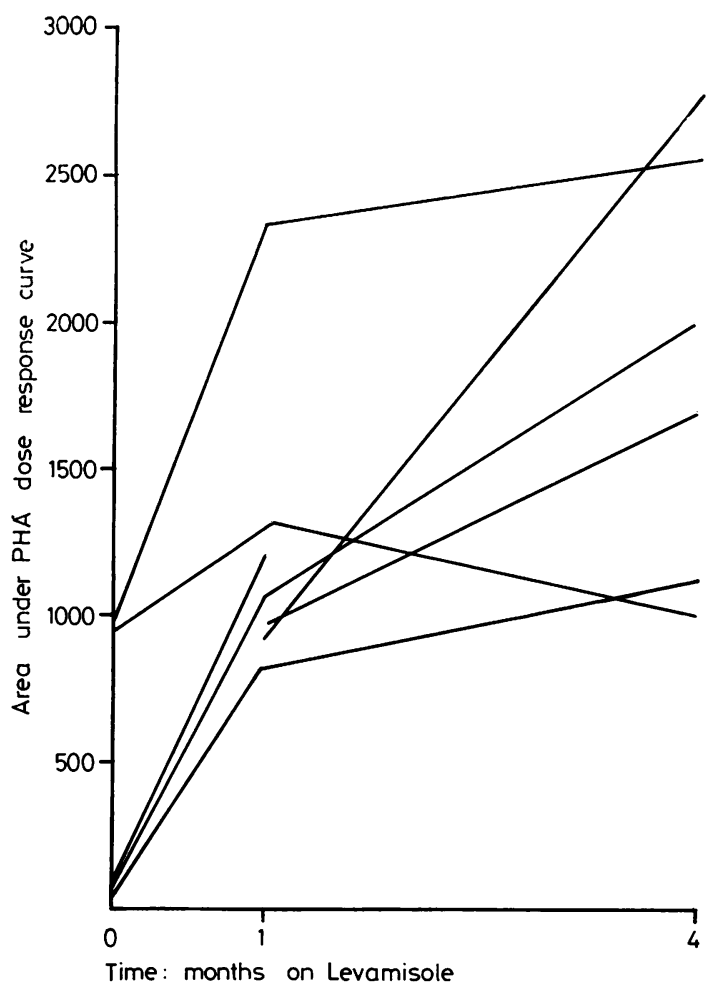

Fig. 3 PHA lymphocyte transformation in patients who developed increased responsiveness during levamisole treatment (group A).

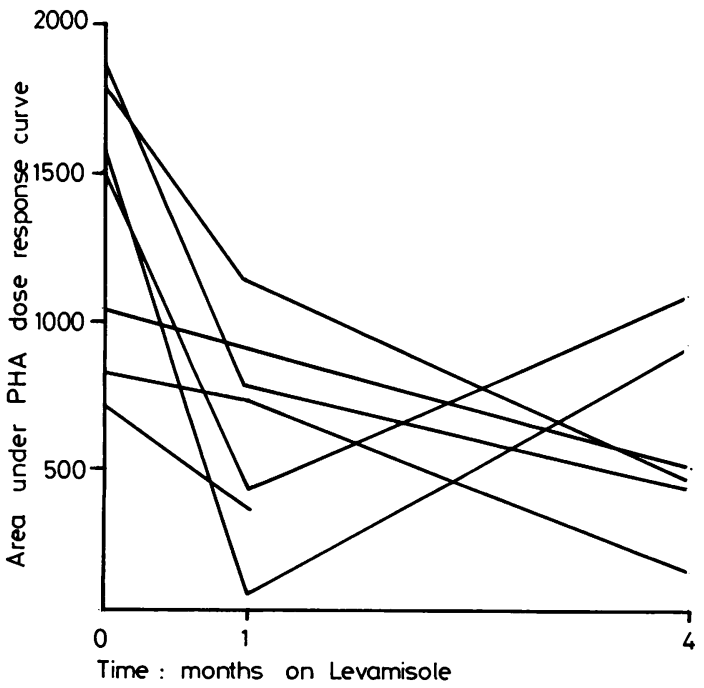

Fig. 4 PHA lymphocyte transformation in patients who developed decreased responsiveness during levamisole treatment (group B). group A were younger and had a tendency to shorter disease duration and more active arthritis, that is, increased ESR, longer duration of morning stiffness, and more swollen joints (Table 5). Both groups combined showed a significant improvement in CRP and ESR after the first 2 months of treatment. The only significant difference in clinical response between group $\mathbf{A}$ and group $\mathbf{B}$ at 2 months was a greater fall in the number of tender joints in group A. After 12 weeks of treatment 6 of 7 patients in group A and only 2 of 7 in group B were improved (Fig. 5, $\mathrm{P}<0.05, \log$ rank test). Three patients in group $B$ discontinued treatment between weeks 12 and 16 owing to rash. At 16 weeks no difference between group $\mathbf{A}$ and group B could be discerned, though all the patients experienced significant improvement in morning stiffness, number of tender and swollen joints, CRP, and ESR. There was no significant correlation between change in PHA stimulation at 16 weeks and degree of clinical improvement.

\section{Discussion}

Levamisole appears to reduce the clinical manifestations of RA, as shown in controlled trials (Huskisson et al., 1976; Runge et al., 1977) and confirmed in the extended studies reported here. The use of levamisole in a variety of diseases may improve depressed CMI (Golding et al., 1976) and phagocytosis (Schmidt and Douglas, 1976), but

Table 5 Degree of change in rheumatoid disease during levamisole treatment related to change in $P H A$ responsiveness: increased $P H A-$ group $A$; decreased PHA-group B

\begin{tabular}{|c|c|c|c|c|}
\hline Parameter & Group & $\begin{array}{l}\text { Initial } \\
\text { value }\end{array}$ & $\begin{array}{l}\text { Change at } \\
2 \mathrm{mo} .\end{array}$ & $\begin{array}{l}\text { Change at } \\
4 \mathrm{mo} \text {. }\end{array}$ \\
\hline $\begin{array}{l}\text { AM stiffness } \\
\text { (minutes) }\end{array}$ & $\begin{array}{l}\mathbf{A} \\
\mathbf{B} \\
\mathbf{A}+\mathbf{B}\end{array}$ & $\begin{array}{l}185 \\
55 \cdot 6 \\
121\end{array}$ & $\begin{array}{l}-118 \\
+9 \cdot 1 \\
-54 \cdot 3\end{array}$ & $\begin{array}{l}-40 \cdot 6 \\
-31 \cdot 4 \\
-36 \cdot 9^{* * *}\end{array}$ \\
\hline $\begin{array}{l}\text { Grip strength } \\
(\mathrm{mmHg})\end{array}$ & $\begin{array}{l}\mathbf{A} \\
\mathbf{B} \\
\mathbf{A}+\mathbf{B}\end{array}$ & $\begin{array}{l}120 \\
111 \\
115\end{array}$ & $\begin{array}{l}-0 \cdot 2 \\
-1.9 \\
-1 \cdot 0\end{array}$ & $\begin{array}{l}+12.6 \\
-1.7 \\
+6.9\end{array}$ \\
\hline $\begin{array}{l}\text { Tender joints } \\
\text { (number) }\end{array}$ & $\begin{array}{l}\mathbf{A} \\
\mathbf{B} \\
\mathbf{A}+\mathbf{B}\end{array}$ & $\begin{array}{l}17 \cdot 9 \\
15 \cdot 5 \\
16 \cdot 7\end{array}$ & $\begin{array}{l}-6 \dagger \\
+1 \cdot 6 \\
-1.5\end{array}$ & $\begin{array}{l}-3 \cdot 7 \\
-2 \cdot 3 \\
-3 \cdot 0^{*}\end{array}$ \\
\hline $\begin{array}{l}\text { Swollen joints } \\
\text { (number) }\end{array}$ & $\begin{array}{l}\mathbf{A} \\
\mathbf{B} \\
\mathbf{A}+\mathbf{B}\end{array}$ & $\begin{array}{l}18 \cdot 0 \\
14 \cdot 5 \\
16 \cdot 2\end{array}$ & $\begin{array}{l}-2 \cdot 5 \\
-1 \cdot 5 \\
-1 \cdot 5\end{array}$ & $\begin{array}{l}-7 \cdot 8 \\
-3 \cdot 5 \\
-5 \cdot 9 * * *\end{array}$ \\
\hline $\begin{array}{l}\text { Creative protein } \\
\mathrm{mg} / 100 \mathrm{ml}\end{array}$ & $\begin{array}{l}\mathbf{A} \\
\mathbf{B} \\
\mathbf{A}+\mathbf{B}\end{array}$ & $\begin{array}{l}3 \cdot 2 \\
3 \cdot 5 \\
3 \cdot 3\end{array}$ & $\begin{array}{l}-0.8 \\
-1 \cdot 2 \\
-1 \cdot 0^{*}\end{array}$ & $\begin{array}{l}-1 \cdot 5 \\
-1 \cdot 0 \\
-1 \cdot 4^{* * *}\end{array}$ \\
\hline $\begin{array}{l}\text { Sedimentation rate } \\
\text { in } 1 \mathrm{~h}\end{array}$ & $\begin{array}{l}\mathbf{A} \\
\mathbf{B} \\
\mathbf{A}+\mathbf{B}\end{array}$ & $\begin{array}{l}55 \cdot 8 \\
34 \cdot 5 \dagger \\
44 \cdot 7\end{array}$ & $\begin{array}{l}-10 \cdot 2 \\
-8 \cdot 9 \\
-9 \cdot 6 * *\end{array}$ & $\begin{array}{l}-18 \cdot 4 \\
-13 \cdot 2 \\
-16 \cdot 1^{\text {*** }}\end{array}$ \\
\hline $\begin{array}{l}\text { Rheumatoid factor } \\
\text { (latex) (Tube } \\
\text { dilution) }\end{array}$ & $\begin{array}{l}\mathbf{A} \\
\mathbf{B} \\
\mathbf{A}+\mathbf{B}\end{array}$ & $\begin{array}{l}5 \\
5 \\
5\end{array}$ & & $\begin{array}{l}0 \\
+2 \cdot 2 \\
+1\end{array}$ \\
\hline
\end{tabular}

* $P<0.05$. ** $P<0.01$. *** $P<0.005$. Final v. initial value. $\dagger P<0.05$ Group A v. Group B. 


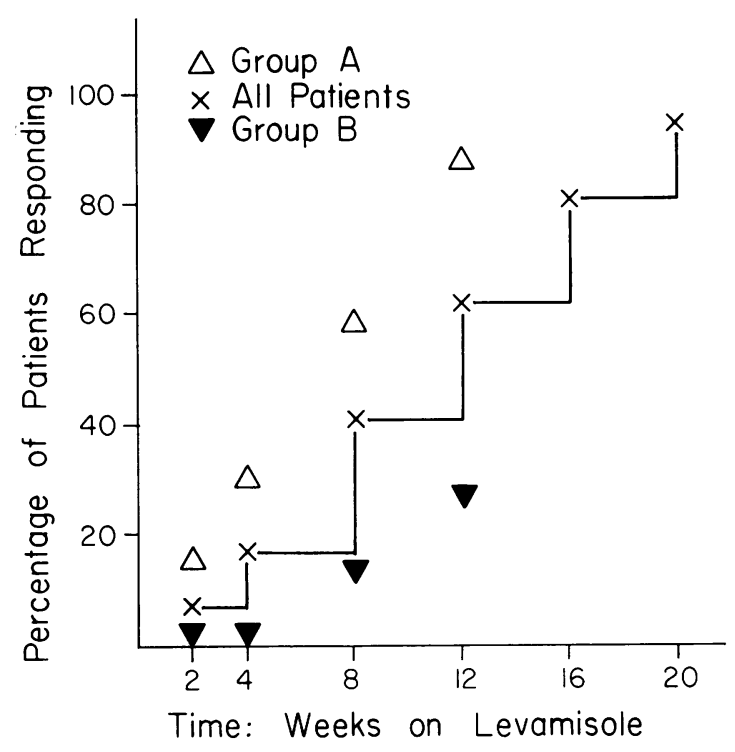

Fig. 5 Rate of improvement during levamisole treatment according to change in $P H A$ responsiveness. Group $A$ increased, group $B$ decreased.

whether this accounts for the amelioration of RA is far from clear. Many problems arise in relating immune changes to clinical events, especially when several measures of improvement are made at multiple intervals. By chance alone one might expect 1 or more laboratory measures to correlate with a clinical measure at one time or another during the course of a drug trial. The life table technique of analysis, with a necessarily arbitrary definition of response, addresses this issue by using all measures as contributions toward a clinically significant degree of response, and permits multiple serial observations to be used for comparing rate of responsiveness. The absolute degree of response at any one time can be assessed by counting the number of parameters improved.

The relationship between improvement PHA responses (group A) and clinical improvement, and depressed PHA responses (group B) and less impressive clinical improvement, should be interpreted with caution. Not only is there an unassessed degree of variability in PHA responses in these sequential studies, but the improved PHA responses may have been due to 'normalisation of lymphocyte function in patients whose responses were previously depressed. Depressed initial responses, and subsequent improvement, may be secondary features rather than primary changes in cellular immune function due to drug therapy.
We noted a more consistent response to SK-SIQ than 3 other skin test antigens; in other studies SK-SD has also been found to be the more sensiti $\overrightarrow{\vec{c}}$ index of depressed CMI in RA (Andrianakos et af 1977). Surprisingly, there was a negative correlatio between enhanced skin test reactions and clinical improvement. In contrast, Huskisson et al. (1976 noted a positive correlation between increased PPIO response and pain reduction in RA patients treate\& with levamisole. The changes in lymphocyte transe formation (LT) with PHA showed even less correlation with clinical response, though we founf some evidence for more rapid clinical improvemerm in patients with enhanced PHA responses during treatment. The relationship of changes in PHAD induced LT and clinical responses has been studied during treatment of RA with other medications Denman et al. (1970), noted that depressed LD improved but normal LT was unchanged during. treatment with chlorambucil or azathioprine. Curtis et al. (1973) reported a tendency toward improve LT with low dose cyclophosphamide (50 to $75 \mathrm{mg}$ day) but Alepa et al. (1970) and Strong et al. (1973 noted depression during treatment with larger doses of cyclophosphamide $(100 \mathrm{mg} / \mathrm{day})$. In the firs studies no correlation was found between improve ment and change in LT. Large doses of cytotoxio drugs and lymphocyte depletion by thoracic duco drainage (Pearson et al., 1975) bring about clinical improvement in the presence of reduced LT.

The pathogenic events in RA might well be to $\overline{0}$ complicated to be reflected accurately in any single immunological measurement. Apparent correlatio $\overrightarrow{\underline{R}}$ with the clinical course may merely indicate secondew ary or indirect changes, similar to the fluctuation is acute phase reactants. Perhaps the changes in the skin test reaction, with its multiplicity of interacting events, are more representative of the net effect of levamisole on lymphocytes, macrophages, and neutrophils than one single nonphysiological lymphocyte response, such as PHA stimulation.

The explanation for levamisole-induced improve ment in RA remains uncertain. The drug maßs aggravate inflammation acutely in some modeb systems (Dieppe et al., 1976a), whereas anti유 inflammatory effects occur after prolonged pre treatment (Dieppe et al., 1976b). Selective enhance ment of deficient suppressor $\mathrm{T}$ cell lymphocyte activity or macrophage function has been suggested (Symoens and Rosenthal, 1977) but not demonstrated directly. In its delayed onset of action in RA and its failure to ameliorate adjuvant arthritis (Traber满 et al., 1976) levamisole resembles penicillamin 8 (Liyanage and Currey, 1972) and gold (Jessop an Currey, 1968). Since one levamisole metabolite is mercaptan (Symoens, 1976), it is possible that \& 
chelating action by free sulfhydryl groups may account for its therapeutic effect.

In common with gold and penicillamine there is a high primary response rate with levamisole, but during prolonged treatment of RA considerable attrition occurs due to both adverse effects and secondary relapses. In our experience, rash has been the main reason for discontinuation, but granulocytopenia has been reported frequently by others (Rosenthal et al., 1977). Almost one-third of our patients who responded initially developed recurrent disease while on continued treatment. The future role of levamisole as a therapeutic agent in RA may depend on more precise definition of optimal doses and treatment schedules and of the clinical characteristics of patients who respond favourably or experience adverse effects. The identification of immunological tests which correlate with and predict these results would also be valuable.

We gratefully acknowledge the valuable assistance of $\mathrm{Dr}$ Richard Oates for statistical advice, Mr David Mallegol of Janssen R\&D, as well as our nurse practitioner Mrs Marie Mou, and the expert laboratory help of Mrs Ella Pinals.

\section{References}

Alepa, F. P., Zvaifler, N. J., and Sliwinski, A. J. (1970). Immunologic effects of cyclophosphamide treatment in rheumatoid arthritis. Arthritis and Rheumatism, 13, 754768.

Andrianakos, A. A., Sharp, J. T., Person, D. A., Lidsky, M. D., and Duffy, J. (1977). Cell mediated immunity in rheumatoid arthritis. Annals of the Rheumatic Diseases, $36,13-20$.

Curtis, J. E., Sharp, J. T., Lidsky, M. D., and Hersh, E. M. (1973). Immune response of patients with rheumatoid arthritis during cyclophosphamide treatment. Arthritis and

Rheumatism, 16, 34-42.

Denman, E. J., Denman, A. M., Greenwood, B. M., Gall, D., and Heath, K. B. (1970). Failure of cytotoxic drugs to suppress immune response of patients with rheumatoid arthritis. Annals of the Rheumatic Diseases, 29, 220-231.

Dieppe, P. A., Willoughby, D. A., Stevens, C., Kirby, J. D., and Huskisson, E. C. (1976a). Symposium on specific therapy for rheumatoid arthritis: specific therapy in new and conventional animal models. Rheumatology and Rehabilitation, 15, 201-206.

Dieppe, P. A., Willoughby, D. A., Huskisson, E. C., and Arrigoni-Martelli, E. (1976b). Pertussis vaccine pleurisy: a model of delayed hypersensitivity. Agents and Actions, 6, 618-621.

Golding, H., Golding, B., Jacobson, R., Lomnitzer, R., Koornhof, A. J., and Rawson, A. R. (1976). In vitro reversal of cellular unresponsiveness induced by levamisole. Clinical and Experimental Immunology, 26, 295-301.

Hartzman, R. J., Bach, M. L., Bach, F. H., Thurman, G. B., and Sell, K. W. (1972). Precipitation of radioactively labelled samples: a semiautomatic multiple sample processer. Cellular Immunology, 4, 182-186.

Horowitz, D. A., and Garrett, M. A. (1977). Lymphocyte reactivity to mitogens in subjects with systemic lupus erythematosus, rheumatoid arthritis and scleroderma. Clinical and Experimental Immunology, 27, 92-99.

Houba, V., Adam, M., Malacek, J., and Tesarek, B. (1964). Delayed hypersensitivity and antibody response in rheumatoid arthritis. Experientia, 20, 522-523.

Huskisson, E. C., Dieppe, P. A., Scott, J., Trapnell, G., Balme, H. W., and Willoughby, D. A. (1976). Immunostimulant therapy with levamisole for rheumatoid arthritis. Lancet, 1, 393-395.

Jessop, J. D., and Currey, H. L. F. (1968). Influence of gold salts on adjuvant arthritis in the rat. Annals of the Rheumatic Diseases, 27, 577-581.

Lance, E. M., and Knight, S. C. (1974). Immunologic reactivity in rheumatoid arthritis. Arthritis and Rheumatism, 17, 513-520.

Liyanage, S. P., and Currey, H. L. F. (1972). Failure of oral D-penicillamine to modify adjuvant arthritis or immune response in the rat. Annals of the Rheumatic Diseases, 31, 521.

Lockshin, M. D., Eisenhauer, A. C., Kohn, R., Weksler, M., Block, S., and Mushlin, S. B. (1975). Cell mediated immunity in rheumatic diseases. Arthritis and Rheumatism, 18, 245-250.

Pearson, C. M., Paulus, H. E., and Machleder, H. I. (1975). The role of the lymphocyte and its products in the propagation of joint disease. Annals of the New York Academy of Sciences, 256, 150-168.

Peto, R., Pike, M. C., Armitage, P., Breslow, N. E., Cox, D. R., Howard, S. V., Mantel, N., McPherson, K., Peto, J., and Smith, P. G. (1977). Design and analysis of randomized clinical trials requiring prolonged observation of each patient. II. Analysis of Examples. British Journal of Cancer, 35, 1-39.

Rosenthal, M., Breysse, Y., Dixon, A. S. J., Franchimont, P., Huskisson, E. C., Schmidt, K. L., Schuermans, Y., Veys, E., Vischer, T. L., Janssen, P. A. J., Amery, W. K., Brugmans, J., DeCree, J., Symoens, J., and MacNair, A. L. (1977). Levamisole and agranulocytosis. Lancet, 1, 904-905.

Runge, L. A., Pinals, R. S., Lourie, S. H., and Tomar, R. H. (1977). Treatment of rheumatoid arthritis with levamisole: a controlled trial. Arthritis and Rheumatism, 20, 1445-1448.

Schmidt, M. E., and Douglas, S. D. (1976). Effects of levamisole on human monocyte function and immunoprotein receptors. Clinical Immunology and Immunopathology, 6, 299-305.

Silverman, H. A., Johnson, J. S., Vaughan, J. H., and McGlamory, J. C. (1976). Altered lymphocyte reactivity in rheumatoid arthritis. Arthritis and Rheumatism, 19, $509-516$.

Strong, J. S., Bartholomew, B. A., and Smith, C. J. (1973). Immunoresponsiveness of patients with rheumatoid arthritis receiving cyclophosphamide or gold salts. Annals of the Rheumatic Diseases, 32, 233-237.

Symoens, J., and Rosenthal, M. (1977). A review of levamisole in the modulation of the immune response: the current experimental and clinical state. Journal of the Reticuloendothelial Society, 21, 175-221.

Symoens, J. (1976). Janssen Pharmaceutica Research Reports, B-2340 Burse, Belgium.

Trabert, U., Rosenthal, M., and Muller, W. (1976). The effect of levamisole on adjuvant arthritis in the rat. Journal of Rheumatology, 3, 166-174.

Verhaegen, H., DeCree, J., DeCock, W., and Verbruggen, F. (1977). Restoration by levamisole of low $E$ rosette forming cells in patients suffering from various diseases. Clinical and Experimental Immunology, 27, 313-318. 